Article

\title{
Simulating Extracellular Glucose Signals Enhances Xylose Metabolism in Recombinant Saccharomyces cerevisiae
}

\author{
Meiling Wu ${ }^{1}$, Hongxing $\mathrm{Li}^{2}$, Shan Wei ${ }^{1}$, Hongyu Wu ${ }^{1}$, Xianwei $\mathrm{Wu}^{1}{ }^{1}$, Xiaoming Bao ${ }^{1,2}$, \\ Jin Hou ${ }^{1}$, Weifeng Liu ${ }^{1}$ and Yu Shen ${ }^{1, *(\mathbb{B})}$ \\ 1 State Key Laboratory of Microbial Technology, Institute of Microbial Technology, Shandong University, \\ Qingdao 266237, China \\ 2 State Key Laboratory of Biobased Material and Green Papermaking, School of Bioengineering, \\ Qi Lu University of Technology, Jinan 250353, China \\ * Correspondence: shenyu@sdu.edu.cn; Tel.: +86-532-5863-2401
}

Received: 16 November 2019; Accepted: 8 January 2020; Published: 10 January 2020

check for updates

\begin{abstract}
Efficient utilization of both glucose and xylose from lignocellulosic biomass would be economically beneficial for biofuel production. Recombinant Saccharomyces cerevisiae strains with essential genes and metabolic networks for xylose metabolism can ferment xylose; however, the efficiency of xylose fermentation is much lower than that of glucose, the preferred carbon source of yeast. Implications from our previous work suggest that activation of the glucose sensing system may benefit xylose metabolism. Here, we show that deleting cAMP phosphodiesterase genes PDE1 and PDE2 increased PKA activity of strains, and consequently, increased xylose utilization. Compared to the wild type strain, the specific xylose consumption rate $\left(\mathrm{r}_{\mathrm{xyl} l o s e}\right)$ of the $p d e 1 \Delta p d e 2 \Delta$ mutant strains increased by $50 \%$; the specific ethanol-producing rate $\left(\mathrm{r}_{\text {ethanol }}\right)$ of the strain increased by $70 \%$. We also show that HXT1 and HXT2 transcription levels slightly increased when xylose was present. We also show that HXT1 and HXT2 transcription levels slightly increased when xylose was present. Deletion of either RGT2 or SNF3 reduced expression of HXT1 in strains cultured in $1 \mathrm{~g} \mathrm{~L}^{-1}$ xylose, which suggests that xylose can bind both Snf3 and Rgt2 and slightly alter their conformations. Deletion of SNF3 significantly weakened the expression of HXT2 in the yeast cultured in $40 \mathrm{~g} \mathrm{~L}^{-1}$ xylose, while deletion of RGT2 did not weaken expression of HXT2, suggesting that $S$. cerevisiae mainly depends on Snf3 to sense a high concentration of xylose $\left(40 \mathrm{~g} \mathrm{~L}^{-1}\right)$. Finally, we show that deletion of Rgt1, increased $\mathrm{r}_{\mathrm{xyl} \text { lose }}$ by $24 \%$ from that of the control. Our findings indicate how $S$. cerevisiae may respond to xylose and this study provides novel targets for further engineering of xylose-fermenting strains.
\end{abstract}

Keywords: budding yeast; xylose metabolism; glucose signaling pathway; PKA; Rgt1

\section{Introduction}

Lignocellulosic biomass is considered as an abundant, renewable, and environment-friendly material for biofuels and chemicals production. Converting the two most abundant sugars in hydrolysates of lignocellulosic materials, glucose and xylose, can increase both the environmental and economic benefits of lignocellulose as a source for biofuels [1,2]. Saccharomyces cerevisiae has been considered a highly competitive cell factory for conversion of lignocellulosic materials to biofuels and chemicals because it is a generally recognized as safe (GRAS) microorganism by the U.S. Food and Drug Administration, has strong glucose-metabolizing capacity, and has been well-studied. However, S. cerevisiae cannot utilize xylose because of its inability to process xylose in its metabolic pathways $[1,3]$.

In recent decades, continuous efforts have been made to construct xylose-utilizing S. cerevisiae and improve the xylose metabolic capacity of these recombinant strains. Xylose reductase (XR) and xylitol 
dehydrogenase (XDH) of Scheffersomyces stipitis or xylose isomerases (XI) of bacteria and fungi have been introduced into $S$. cerevisiae to build pathways for xylose metabolism. In recombinant $S$. cerevisiae strains, xylose is transported by hexose transporters and metabolized in sequence through the XR-XDH or XI, pentose phosphate, and glycolysis pathways to produce pyruvate, which is then converted to ethanol and other products [3-5]. Therefore, the genes of xylulokinase and the non-oxidative part of the pentose phosphate pathway (PPP) were overexpressed to enhance the downstream flux of xylose metabolism [6-8].

Unfortunately, the attempts of metabolic engineering mentioned above are far from enough, and the adaptive evolution in the medium with xylose as the sole carbon source is necessary to produce a S. cerevisiae strain that can efficiently utilize xylose [8-12]. Many researchers have endeavored to reveal the differences in the "omics" between the evolved strains (with high xylose utilization capacity) and their parents (with low xylose utilization capacity) [11,13-15], as well as the differences in the "omics" between the strains cultured in xylose and in glucose $[16,17]$. The results suggested that an important reason that limited the xylose fermentation rate is the fact that $S$. cerevisiae lacks a signaling pathway to recognize xylose as a carbon source and regulate the cells to convert to a state that promotes xylose utilization. For another, our previous work suggests that extracellular glucose signals can promote xylose utilization. In a strain that could transport xylose but not glucose intracellularly, we observed that xylose metabolism was enhanced by the presence of extracellular glucose [18] (Figure A1). Extensive studies on glucose signaling pathways and their controls on glucose metabolism showed that efficient hexose transporters and glycolysis, which are the factors for efficient xylose metabolism, depends on activation of glucose signaling pathways. Unfortunately, how these signaling pathways may respond to xylose is not clear.

There are two signaling pathways that respond to extracellular glucose [19]. The first is the cAMP-PKA pathway (Figure 1A) where the transmembrane protein, Gpr1, undergoes an allosteric effect when extracellular glucose or sucrose binds to it. Then, the allosteric Gpr1 stimulates the transition of the small g protein Gpa2 from an inactive state (binding with GDP) to an active state (binding with GTP). The GTP-bound Gpa2 activates adenylate cyclase Cyr1 which catalyzes the conversion of ATP to CAMP and subsequently increases the intracellular levels of cAMP. cAMP binds to the regulatory subunit Bcy1 of PKA and exposes the active site of Tpk1/Tpk2/Tpk3, thus activating PKA. Meanwhile, the cAMP-PKA pathway is also regulated by an intracellular protein, Ras. Intracellular glucose and its metabolites stimulate the GDP-bound Ras (inactive) to convert to GTP-bound Ras (active). The active Ras can also increase Cyr1 activity and consequently, PKA activity. Additional proteins that affect the pathway are two cAMP phosphodiesterases, Pde1 and Pde2, that catalyze cAMP to AMP to prevent the overactivation of PKA [19]. The active PKA up-regulates glycolysis and down-regulates gluconeogenesis at both transcriptional and translational levels [20,21]. Increased activity of PKA benefits xylose utilization because xylose metabolism occurs through the PPP and glycolysis pathway.

In the Rgt2/Snf3-Rgt1 pathway, which also responds to extracellular glucose (Figure 1B), high and low levels of extracellular glucose are sensed by the membrane-spanning proteins Rgt2 and Snf3, respectively [22]. The signal is then relayed into the cell, leading to the phosphorylation-dependent degradation of Mth1 and Std1, which are co-repressors necessary for the DNA-binding of Rgt1. The elimination of Mth1 and Std1 exposes Rgt1 to phosphorylation, which releases it from gene promoters and derepresses the expression of target genes, including the ones encoding hexose transporters $[19,23]$. Lacking a xylose transporter, the transport of xylose in S. cerevisiae depends on these hexose transporters (HXT) [24]. Thus, the repression of Rgt1 is expected to negatively affect hexose transporter genes and thus xylose utilization. In a recent work, researchers were able to show that extracellular xylose can induce the fluorescent signal of the green fluorescent protein gene (yEGFP3) expressed under the control of the HXT1, 2, and 4 promoters. Their data suggest that the Rgt2/Snf3-Rgt1 pathway responds to extracellular xylose, although the mechanistic details are still not clear [25]. 

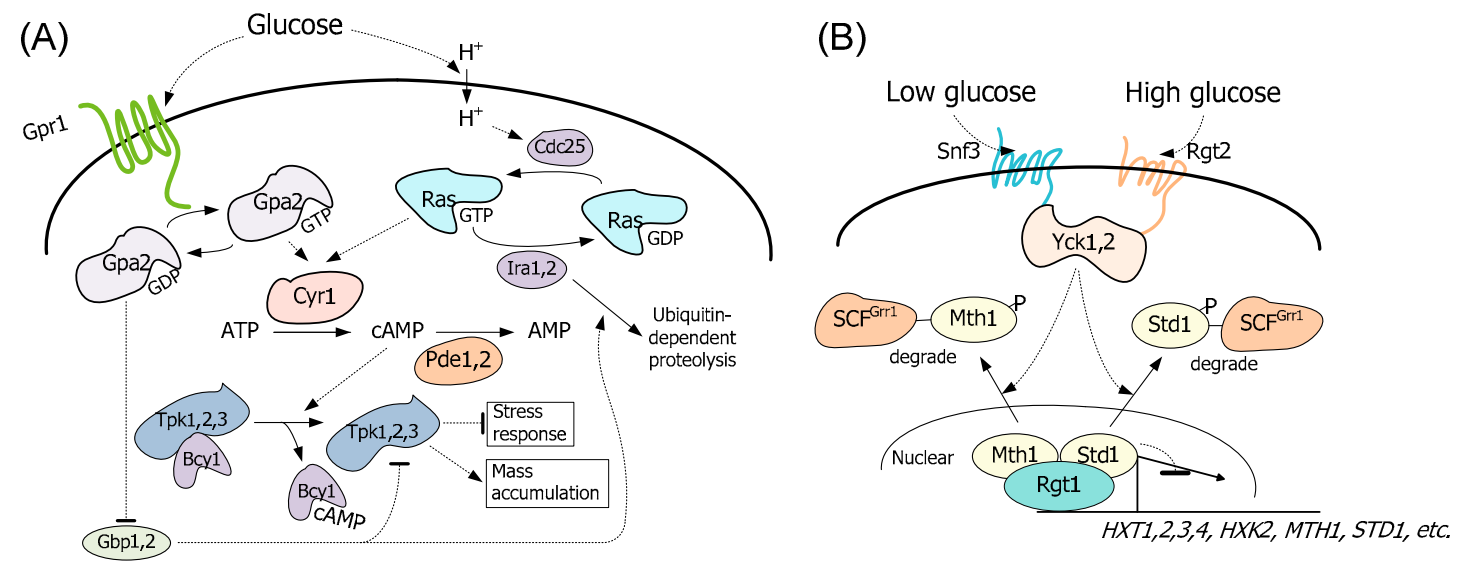

Figure 1. Two signaling pathways that respond to extracellular glucose in Saccharomyces cerevisiae. (A) The cAMP-PKA pathway. The membrane protein Gpr1 serves as a receptor for extracellular glucose and stimulates activation of Gpa2, which in turn stimulates adenylyl cyclase Cyr1. Ras responds to glucose-stimulated intracellular acidification and also stimulates Cyr1. Cellular levels of cAMP were determined by the competing activities of synthesis from ATP via Cyr1 and degradation to AMP by phosphodiesterases, Pde1, and Pde2. A high level of cAMP activates PKA by binding to the regulatory subunits Bcy1 which releases the catalytic subunits Tpk1, 2, 3. Additionally, Gpa2 can activate PKA by inhibiting Gpb1, 2, which inhibits PKA and promotes ubiquitin-dependent proteolysis of Ira2. The active PKA suppresses the stress response and stimulates growth. (B) The Snf3/Rgt2-Rgt1 pathway. High and low levels of extracellular glucose are sensed by the membrane-spanning proteins Rgt2 and Snf3, respectively. Glucose binds to the glucose receptors Snf3 and Rgt2 and stimulates the Yck kinases that phosphorylate Std1 and Mth1. The phosphorylated Std1 and Mth1 are then degraded by ubiquitin-dependent proteolysis. Without corepressors Std1 and Mth1, Rgt1 does not repress the expression of genes such as HXTs, etc.

The aims of the present work were to determine how signals from extracellular glucose can enhance xylose utilization and the mechanism of how S. cerevisiae can sense extracellular xylose. Here, we demonstrated that the PKA level in cells cultured on xylose was much lower than that of cells cultured on glucose. Additionally, expression of the Gpa ${ }^{G 132 V}$ allele or knock outs of both PDE1 and PDE2 increased the PKA activity, regulated expression of carbohydrate metabolism genes, and increased the xylose consumption rate of the $S$. cerevisiae strain. We also explored how $S$. cerevisiae may sense extracellular xylose by examining the transcriptional levels of HXT1 and HXT2 in rgt2 $\Delta$ and $s n f 3 \Delta$ strains cultured in media with different levels of glucose and xylose. The results demonstrate that Rgt2 and Snf3 can only weakly respond to high concentrations of xylose and slightly increase the expression of transporter genes. Then, we demonstrated that deleting Rgt1 improved the expression of transporter genes and xylose utilization. Our work will improve our understanding of the effect of xylose on the major glucose signaling pathways in S. cerevisiae and demonstrates promising strategies for delivering simulated glucose signals to induce $S$. cerevisiae cells to modify their gene-expression state to a state fit for xylose utilization.

\section{Materials and Methods}

\subsection{Strains and Plasmids}

All S. cerevisiae strains and plasmids are listed in Table 1. The primers are listed in Table A1.

Strain BSL01 (BSPC039 [12] derivative; pJX7 [26]) was used as the parent strain and control. The strain BSL06(GPA2 $\left.{ }^{G 132 V}\right)$ was obtained by integrating GPA2 $2^{132 V}$ at the GRE3 site of BSL01. The fragment GRE3-ty1-loxP-KanMX-loxP-TEF1p-GPA2 G132V-PGKt-GRE3-ty2 was used for the integration. The homologous arms GRE3-ty1 and GRE3-ty2 were cloned from the CEN.PK113-5D [27] genome. The selection marker loxP-KanMX-loxP was cloned from 
plasmid pUG6 [28]. The GPA2 ${ }^{\mathrm{G} 132 \mathrm{~V}}$ ORF fragment was obtained by fusion PCR, using the CEN.PK113-5D genome as a template, and then treated with BamHI and SbfI and ligated between TEF1p and PGKt of plasmid pJFE1 [26]. Then, the expression cassettes TEF1p-GPA2 ${ }^{G 132 V}-P G K t$, GRE3-ty1, GRE3-ty2, and loxP-KanMX-loxP were ligated by fusion PCR to obtain the full fragment GRE3-ty1-loxP-KanMX-loxP-TEF1p-GPA2 ${ }^{G 132 V}$-PGKt-GRE3-ty2. The KanMX marker was discarded by transferring plasmid YEp-CH [26] into the strains and inducing the expression of the Cre recombinase. Thus, the KanMX4 cassette between the two loxP sequences was removed by the recombination between the two loxP sites. The construction process of BSL08(RAS2 $\left.{ }^{G 19 V}\right)$ was similar to that of BSL06(Gpa2 $\left.{ }^{\mathrm{G} 132 \mathrm{~V}}\right)$.

Table 1. Strains and plasmids used in this work.

\begin{tabular}{|c|c|c|}
\hline S. cerevisiae Strains and Plasmids & Description & Sources \\
\hline \multicolumn{3}{|l|}{ Plasmids } \\
\hline pUG6 & E. coli plasmid with segment LoxP-KanMX44-LoxP & [28] \\
\hline pJFE1 & YCplac33; CEN, Amp $p^{r}$, URA3, TEF1p-PGK1t & [26] \\
\hline YEp-CH & YEp; containing hygromycin $\mathrm{B}$ resistant gene and $\mathrm{Cre}$ gene under $\mathrm{GAL2}$ regulative regulation promoter & [26] \\
\hline \multicolumn{3}{|l|}{ S. cerevisiae Strains } \\
\hline CEN.PK 113-5D & MATa; ura3-53, belongs to CEN.PK strain family & [27] \\
\hline BSL01 & $\begin{array}{l}\text { BSPC039 derivative; pJX7 } \\
\text { BKLT ADHT IT LI TRPET TUA }\end{array}$ & This work \\
\hline BSL06 & BSL01 derivative; $G P A 2^{G 132 V}$ & This work \\
\hline BSL08 & BSL01 derivative; $R A S 2^{G 19 V}$ & This work \\
\hline BSL10 & BSL01 derivative; $p d e 1 \Delta$ & This work \\
\hline BSL16 & BSL01 derivative; $p d e 1 \Delta ; p d e 2 \Delta$ & This work \\
\hline BSL20 & BSL01 derivative; rgt1 $\Delta$ & This work \\
\hline
\end{tabular}

The deletions of genes PDE1, PDE2, RGT1, SNF3, and RGT2 were all performed by replacing the target gene with the KanMX4 cassette via homologous recombination, and then the KanMX4 was removed as mentioned above. The integration arms of genes were all cloned from the CEN.PK113-5D genome.

\subsection{Cultivation Conditions and Batch Fermentation}

BSL01 and its derivatives were cultured in SD-URA medium, which contained $1.7 \mathrm{~g} \mathrm{~L}^{-1}$ yeast nitrogen base (YNB, Sangon, Shanghai, China), $5 \mathrm{~g} \mathrm{~L}^{-1}$ ammonium sulfate (Sangon, Shanghai, China), $0.77 \mathrm{~g} \mathrm{~L}^{-1}$ CSM-URA (MP Biomedicals, Solon, $\mathrm{OH}, \mathrm{USA}$ ), and $20 \mathrm{~g} \mathrm{~L}^{-1}$ glucose or xylose as the carbon source. BSWW1 $(\operatorname{snf} 3 \Delta)$ and BSWW2 $(r g t 2 \Delta)$ were cultured in YPD medium. For selection of transformants, $800 \mathrm{mg} \mathrm{L}^{-1} \mathrm{G} 418$ or $400 \mathrm{mg} \mathrm{L}^{-1}$ hygromycin B was added into the medium when necessary. The fermentations were performed in SD-URA medium with $20 \mathrm{~g} \mathrm{~L}^{-1}$ xylose and/or $20 \mathrm{~g} \mathrm{~L}^{-1}$ glucose at $30^{\circ} \mathrm{C}$. A single colony from a plate of SD-URA medium was incubated in the liquid medium and collected in the middle of exponential growth to inoculate $100-\mathrm{mL}$ flasks containing $40 \mathrm{~mL}$ fermentation medium. The initial biomass was $0.23 \mathrm{~g} \mathrm{DCW} \mathrm{L}^{-1}$ and $\mathrm{pH}$ was 4.5 . The fermentation was performed at $200 \mathrm{rpm}, 30^{\circ} \mathrm{C}$.

\subsection{Determination of cAMP}

Preparation of samples was performed as instructed in the manual of the cAMP Direct Immunoassay Kit (BioVision, Milpitas, CA, USA). Cells in the middle of exponential growth were collected by centrifugation at $6000 \mathrm{rpm}$ for $5 \mathrm{~min}$ at $4{ }^{\circ} \mathrm{C}$. The $80 \mathrm{mg}$ (DCW) cells were cooled in liquid nitrogen and resuspended with $500 \mu \mathrm{L} \mathrm{HCl}\left(0.2 \mathrm{M}\right.$ pre-cooled to $\left.4^{\circ} \mathrm{C}\right)$ and $0.6 \mathrm{~g}$ acid-washed glass beads $(\varphi=0.5 \mathrm{~mm}$ ). Then cells were lysed using a FastPrep cell homogenizer (Thermo Savant, Carlsbad, CA, USA) at a speed of $5000 \mathrm{rpm}$ for $30 \mathrm{~s}$ and repeated twice. The homogenate was centrifuged at $13,000 \mathrm{rpm}$ for $5 \mathrm{~min}$ at $4{ }^{\circ} \mathrm{C}$, and the cAMP levels in this supernatant were determined by the cAMP 
Direct Immunoassay Kit (BioVision, Milpitas, CA, USA). The t-tests were applied to evaluate the differences between means.

\subsection{Assay of Trehalase Activity}

The preparation of crude enzyme samples and the assay of trehalase activity were performed based on a previously reported method [29]. Cells were collected by centrifugation at $6000 \mathrm{rpm}$ for $5 \mathrm{~min}$ at $4{ }^{\circ} \mathrm{C}$. The $40 \mathrm{mg}(\mathrm{DCW})$ cells were cooled in liquid nitrogen and resuspended with $500 \mu \mathrm{L}$ HEPES ( $\mathrm{pH} 7.0$ ) and $0.8 \mathrm{~g}$ acid-washed glass beads $(\varphi=0.5 \mathrm{~mm})$. These cells were lysed using a FastPrep cell homogenizer (Thermo Savant, Carlsbad, CA, USA) at a speed of $5000 \mathrm{rpm}$ for $30 \mathrm{~s}$ and repeated five times. The homogenate was centrifuged at $13,000 \mathrm{rpm}$ for $5 \mathrm{~min}$ at $4{ }^{\circ} \mathrm{C}$, and the supernatant was used as the crude enzyme sample. The total cellular protein concentration was measured using a BCA protein assay reagent kit (Sangon Biotech Co., Ltd., Shanghai, China). Trehalase activities were determined at $30^{\circ} \mathrm{C}$ by measuring the glucose produced by hydrolysis of trehalose. Reactions contained $10 \mu \mathrm{L}$ extract and $140 \mu \mathrm{L}$ water in $100 \mu \mathrm{L}$ substrate buffer $(250 \mathrm{mM}$ trehalose in $50 \mathrm{mM}$ HEPES buffer, $\mathrm{pH} 7$, with $125 \mu \mathrm{M} \mathrm{CaC1}_{2}$ ). They were incubated at $30{ }^{\circ} \mathrm{C}$ for $30 \mathrm{~min}$ and then immediately halted by boiling for $3 \mathrm{~min}$ at $100{ }^{\circ} \mathrm{C}$. The amount of glucose produced was determined by a D-Glucose (GOPOD Format) Assay Kit (Megazyme, Dublin, Ireland). Specific activity of trehalase was expressed as nmol glucose liberated $\mathrm{min}^{-1}(\mathrm{mg} \text { protein })^{-1}$. The t-tests were applied to evaluate the differences between means.

\subsection{Analysis of Metabolites}

The concentrations of glucose, xylose, and ethanol were determined using the Prominence LC-20A HPLC (Shimadzu, Kyoto, Japan) equipped with an Aminex HPX-87H ion-exchange column (Bio-Rad, Hercules, CA, USA) and a refractive index detector RID-10A. Samples were eluted from the column at $45^{\circ} \mathrm{C}$ with $5 \mathrm{mmol} \mathrm{L}^{-1} \mathrm{~h}_{2} \mathrm{SO}_{4}$ at a flow rate of $0.6 \mathrm{~mL} \mathrm{~min}^{-1}$ [16].

\subsection{Calculation of Physiological Parameters}

The cell density $\left(\mathrm{OD}_{600}\right)$ was determined with a UV-visible spectrophotometer (Eppendorf, Hamburg, Germany). The biomass was estimated according to the correlation of measured OD 600 and dry weight [16]. One unit of $\mathrm{OD}_{600}$ equaled $0.208 \mathrm{~g} \mathrm{DCW} \mathrm{L}{ }^{-1}$. The specific growth rate $(\mu)$ was the regression coefficient of the log-linear regression of the $\mathrm{OD}_{600}$ versus time during the exponential growth phase. The specific xylose consumption rate $\left(r_{x y l o s e}\right)$, specific glucose consumption rate ( $\left.\mathrm{r}_{\text {glucose }}\right)$, and specific ethanol production rate $\left(\mathrm{r}_{\text {ethanol }}\right)$ were calculated using the following Equation (1) as previously described [12]:

$$
\mathrm{r}=\frac{A_{n}-A_{m}}{\frac{1}{2} \sum_{i=m+1}^{n}\left(B_{i}+B_{i-1}\right) \times\left(t_{i}-t_{i-1}\right)},
$$

where $\mathrm{r}$ is the specific utilization or production rate during the phase from sampling point $m$ to sampling point $n$; and $A, B$, and $t$ are the metabolite concentration, biomass concentration, and time, respectively, at sampling points $n, i$, and $m$.

The $t$-tests were applied to evaluate the differences between means.

\subsection{Quantitative PCR}

qPCR data were analyzed according to the $2^{-\Delta \Delta C t}$ method [30]. RNA was extracted from exponentially growing cells using a UNlQ-10 Column Trizol Total RNA Isolation Kit (Sangon Biotech Co., Ltd., Shanghai, China). The cDNA was obtained using a PrimeScript ${ }^{\mathrm{TM}}$ RT reagent Kit (TaKaRa, Shiga, Japan). The gene transcription levels were determined using the equation $\mathrm{N}$

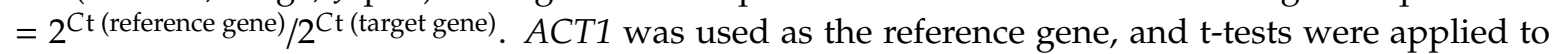
evaluate the differences between means [16]. 


\section{Results}

\subsection{Expression of the GPA2 ${ }^{G 132 V}$ Allele and Deletion of Both PDE1 and PDE2 Increased PKA Activity in S. cerevisiae}

To investigate differences in cAMP-PKA responses in S. cerevisiae to glucose and xylose, intracellular cAMP concentration and trehalase activity level of strains cultured in media using glucose or xylose as the sole carbon source were determined, since trehalase activity is tightly connected to PKA activity [31]. The results showed that intracellular cAMP concentrations of the strain BSL01 in glucose and xylose fermentation were similar (Figure 2). However, intracellular trehalase activity of yeast cells in xylose fermentation was only $35 \%$ of that in glucose fermentation (Figure 2), implying that the PKA activity of cells in xylose fermentation was lower than that in glucose fermentation.
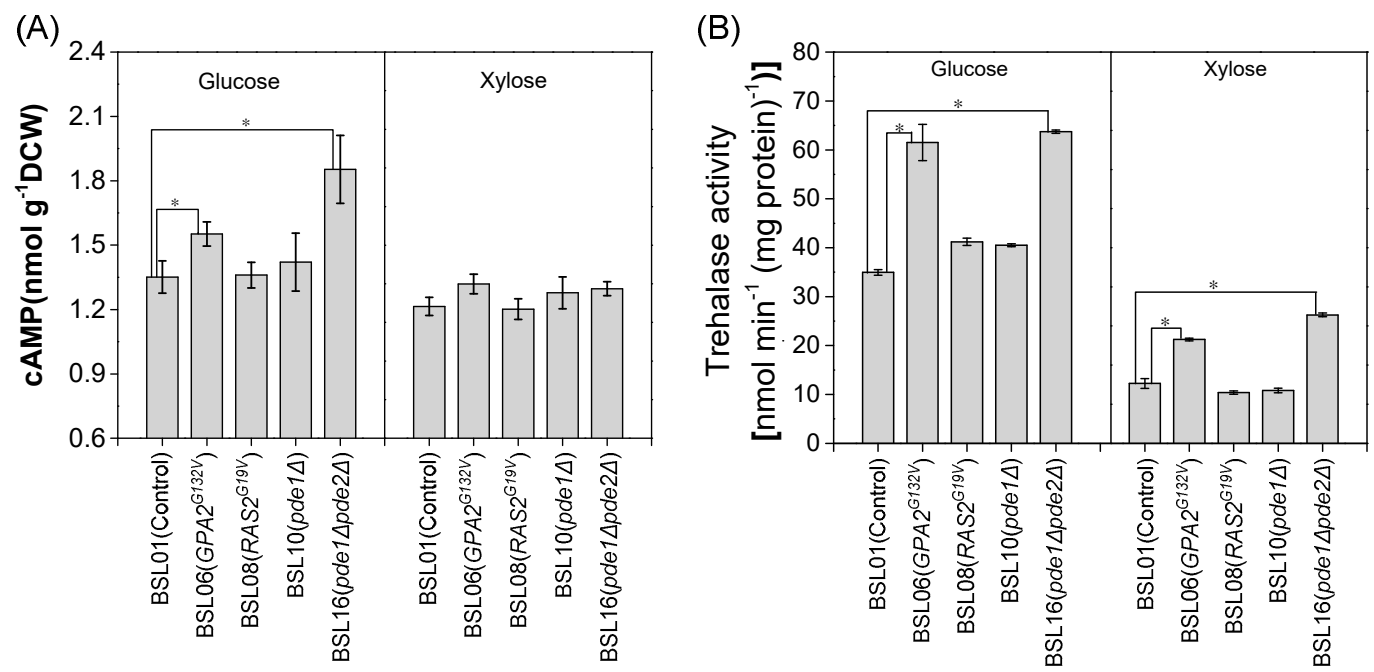

Figure 2. Amounts of cAMP (A) and trehalase activity (B) of recombinant S. cerevisiae strains. Cells with an initial $\mathrm{OD}_{600}$ of 1.0 were cultured at $30{ }^{\circ} \mathrm{C}$ in shake flasks at $200 \mathrm{rpm}$. Cells were sampled at mid-exponential growth phase, specifically at $12,12.5$, and $13 \mathrm{~h}$ of xylose fermentation; and at $4.5,5$, and $5.5 \mathrm{~h}$ of glucose fermentation. At each time point, three samples were taken, one from each of the triplicate fermentations. Data are mean values \pm standard deviations of the three samples collected per time point. ${ }^{*} p$ value $<0.05$

Three genetic strategies were used to increase PKA activity. The first strategy promoted expression of the GPA2 ${ }^{G 132 V}$ allele, which can constitutively activate the cAMP-PKA pathway whether or not Gpr1 senses the extracellular glucose signals [21,32]. The second promoted expression of the RAS2G19V allele, which may induce high levels of cAMP and PKA activity [21,33]. In the third method, we deleted the genes encoding two phosphodiesterase (both Pde1 and Pde2 or only the primary one, Pde1), which functions in the feedback control by PKA in degrading cAMP [19]. Thus, we constructed

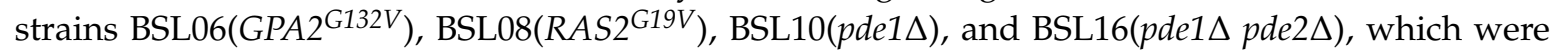
derived from the xylose-utilizing strain BSL01. The BSL01 strain consisted of a xylose isomerase gene cloned from a metagenomics library of the bovine rumen microbiome. Moreover, the genes encoding xylulokinase and the enzymes in the non-oxidative part of the PPP were overexpressed in BSL01.

The results show that expressing GPA2 ${ }^{G 132 V}$ and deleting both PDE1 and PDE2 increased the intracellular cAMP concentration by respectively $15 \%$ and $30 \%$ in glucose fermentation (Figure $2 \mathrm{~A}$ ). Consistent with this, trehalase activity increased by respectively $76 \%$ and $82 \%$ (Figure $2 \mathrm{~B}$ ), which implied the increase of PKA activity. In xylose fermentation, cAMP levels of the five strains were similar. However, expressing GPA2 ${ }^{G 132 V}$ and deleting both PDE1 and PDE2 increased trehalase activity by respectively $73 \%$ and $114 \%$. Thus, the trehalase activity of these two strains in xylose fermentation respectively reached $61 \%$ and $70 \%$ of that of BSL01 in glucose fermentation (Figure $2 \mathrm{~B}$ ). In contrast, 
expressing RAS2 ${ }^{G 19 V}$ and only deleting PDE1 had no effect on cAMP level and trehalase activity in both glucose and xylose fermentations (Figure 2).

\subsection{Expression of GPA2 ${ }^{\mathrm{G} 132 \mathrm{~V}}$ Allele and Deletion of Both PDE1 and PDE2 Affected Glucose and Xylose Metabolism}

The fermentation dynamics of strains BSL06(GPA2 $\left.{ }^{\mathrm{G} 132 V}\right)$, BSL16(pde1 $\left.\Delta p d e 2 \Delta\right)$, and the control BSL01 were compared. The results revealed that the specific growth rates $(\mu)$ of these strains with $20 \mathrm{~g} \mathrm{~L}^{-1}$ xylose as the sole carbon source were the same (Figure 3 ). The specific xylose consumption rates ( $\mathrm{r}_{x y l o s e}$, xylose consumed per unit of cell mass) of BSL06(GPA2 ${ }^{G 132 V}$ ) and BSL16(pde1 $\left.\Delta p d e 2 \Delta\right)$ were $19 \%$ and $51 \%$ higher than that of BSL01, respectively. The specific ethanol production rates $\left(\mathrm{r}_{\text {ethanol }}\right)$ of BSL06(GPA2 ${ }^{\mathrm{G} 132 V}$ ) and BSL16(pde1 $\left.\Delta p d e 2 \Delta\right)$ were greater by $74 \%$ and $72 \%$, respectively, compared to that of BSL01 (Figure 3, Table 2).

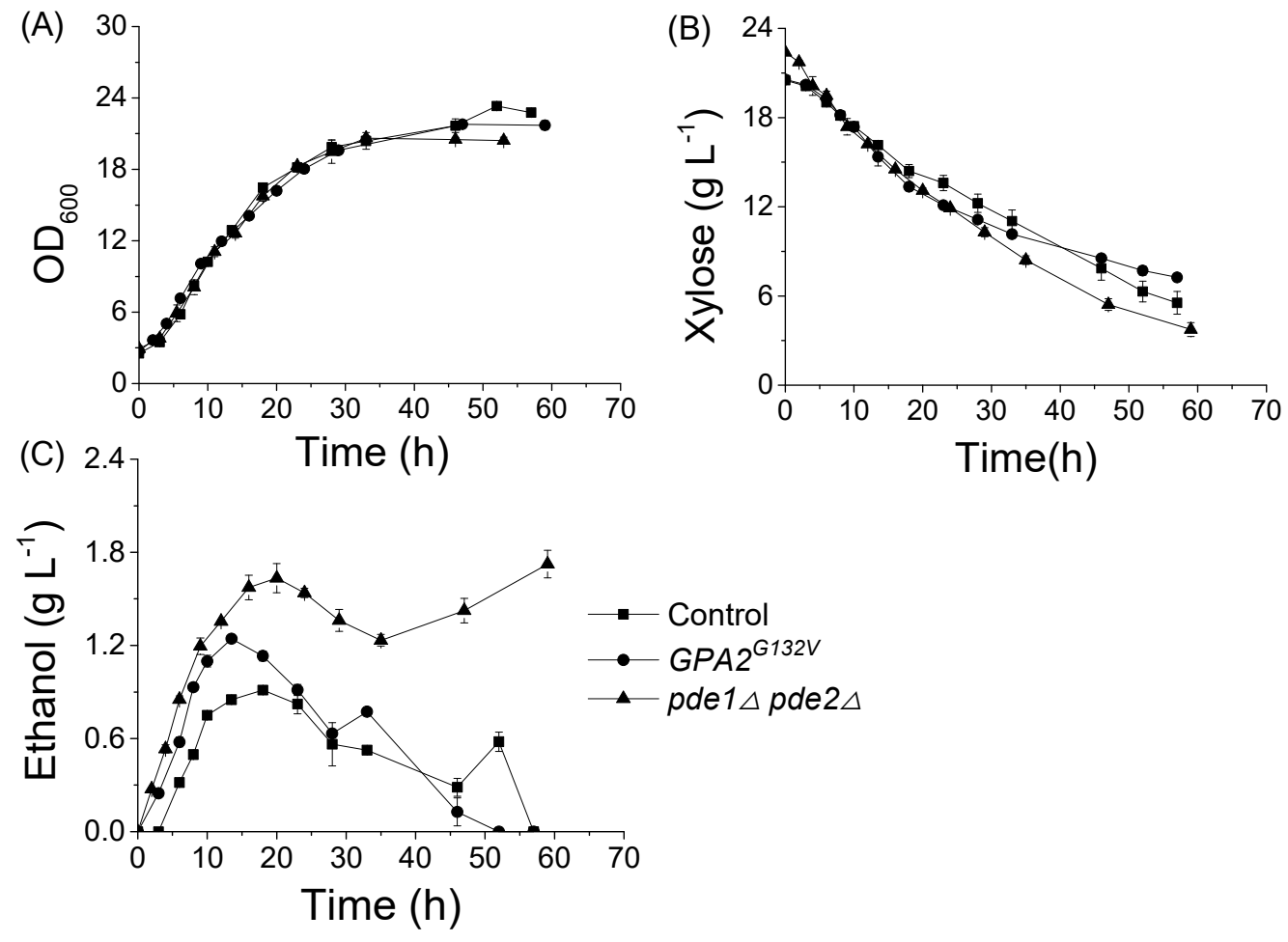

Figure 3. Xylose fermentation characteristics of recombinant S. cerevisiae strains. The (A), growth; (B) xylose consumption; and (C), ethanol production of strains. BSL06 $\left(G P A 2^{G 132 V}\right)(\bullet)$, BSL16(pde1 $1 \Delta$ pde2 $\Delta)(\mathbf{\Lambda})$, and the control BSL01 $(\mathbf{\bullet})$. Cells with initial $\mathrm{OD}_{600}$ of $2.5\left(\approx 0.5 \mathrm{~g} \mathrm{~L}^{-1}\right.$ biomass $)$ were cultured in SC-URA medium supplemented with $20 \mathrm{~g} \mathrm{~L}^{-1}$ xylose at $30^{\circ} \mathrm{C}$ and $200 \mathrm{rpm}$ in shake flasks. Data are the mean values of triplicate tests.

Table 2. The xylose fermentation and glucose-xylose co-fermentation characteristics of strains.

\begin{tabular}{|c|c|c|c|c|c|}
\hline \multirow[b]{2}{*}{ Strains } & \multicolumn{2}{|c|}{ Xylose Fermentation } & \multicolumn{3}{|c|}{ Glucose-Xylose Co-Fermentation } \\
\hline & $\begin{array}{c}\text { Specific Xylose } \\
\text { Consumption Rates } \\
\left(\mathrm{g} \mathrm{L}^{-1} \mathrm{~h}^{-1} \mathrm{~g}^{-1} \text { DCW) }\right.\end{array}$ & $\begin{array}{c}\text { Specific Ethanol } \\
\text { Production Rates } \\
\left(\mathrm{g} \mathrm{L}^{-1} \mathrm{~h}^{-1} \mathrm{~g}^{-1} \mathrm{DCW}\right)\end{array}$ & $\begin{array}{c}\text { Specific Glucose } \\
\text { Consumption Rates } \\
\left(\mathrm{g} \mathrm{L}^{-1} \mathrm{~h}^{-1} \mathrm{~g}^{-1} \text { DCW) }\right.\end{array}$ & $\begin{array}{c}\text { Specific Xylose } \\
\text { Consumption Rates } \\
\left(\mathrm{g} \mathrm{L}^{-1} \mathrm{~h}^{-1} \mathrm{~g}^{-1} \text { DCW) }\right.\end{array}$ & $\begin{array}{c}\text { Specific Ethanol } \\
\text { Production Rates } \\
\left(\mathrm{g} \mathrm{L}^{-1} \mathrm{~h}^{-1} \mathrm{~g}^{-1} \mathrm{DCW}\right)\end{array}$ \\
\hline BSL01(Control) & $0.103 \pm 0.003$ & $0.047 \pm 0.002$ & $1.218 \pm 0.004$ & $0.046 \pm 0.002$ & $0.428 \pm 0.005$ \\
\hline BSL06(GPA2 $\left.{ }^{G 132 V}\right)$ & $0.123 \pm 0.003$ & $0.082 \pm 0.001^{* * *}$ & $1.354 \pm 0.019 * *$ & $0.0481 \pm 0.002$ & $0.489 \pm 0.002^{* * *}$ \\
\hline BSL16 $(p d e 1 \Delta p d e 2 \Delta)$ & $0.156 \pm 0.001 * *$ & $0.081 \pm 0.003^{* *}$ & $1.260 \pm 0.008 *$ & $0.068 \pm 0.004 *$ & $0.523 \pm 0.005 * * *$ \\
\hline
\end{tabular}

The fermentations were performed in the $100 \mathrm{~mL}$ shake flasks with $40 \mathrm{~mL}$ medium. For the xylose fermentation, the medium was SC-URA with $20 \mathrm{~g} \mathrm{~L}^{-1}$ xylose as carbon source; for the glucose-xylose co-fermentation, the medium was SC-URA with $20 \mathrm{~g} \mathrm{~L}^{-1}$ glucose and $20 \mathrm{~g} \mathrm{~L}^{-1}$ xylose medium. The cells were cultured at $30{ }^{\circ} \mathrm{C}, 200 \mathrm{rpm}$, with initial $\mathrm{OD}_{600}$ of $2.5\left(\approx 0.5 \mathrm{~g} \mathrm{~L}^{-1}\right.$ biomass). The experiments were performed in triplicate. The values are given as the averages \pm standard deviations of three measurements. DCW, dry cell weight. ${ }^{*} p$ value $<0.05$; ${ }^{* *} p$ value $<$ $0.01 ;{ }^{* * *} p$ value $<0.005$. 
In the co-fermentation of $20 \mathrm{~g} \mathrm{~L}^{-1}$ glucose and $20 \mathrm{~g} \mathrm{~L}^{-1}$ xylose as carbon sources, the $\mu$ of strains were also similar (Figure 4). However, BSL06(GPA2 ${ }^{G 132 V}$ ) and BSL16(pde1 $\left.\Delta p d e 2 \Delta\right)$ shifted out of the exponential growth phase before BSL01's shift. Correspondingly, biomass yields of BSL06(GPA2 ${ }^{\text {G132V }}$ ) and BSL16 (pde1 $\Delta p d e 2 \Delta$ ) were lower than biomass of BSL01. Interestingly, the lower biomass yields did not result in lower consumption rates of sugars; in fact, sugar metabolism rates of the mutant strains were greater than the rate of the wild type. Compared to BSL01, the specific glucose consumption rate $\left(\mathrm{r}_{\text {glucose }}\right)$ of BSL06(GPA2 ${ }^{G 132 V}$ ) increased by $11.1 \% ; \mathrm{r}_{\text {xylose }}$ of BSL16 $(p d e 1 \Delta p d e 2 \Delta)$ increased by $48 \%$; and $r_{\text {ethanol of BSL06(GPA2 }}{ }^{G 132 V}$ ) and BSL16(pde1 $\left.\Delta p d e 2 \Delta\right)$ increased by $14 \%$ and $22 \%$, respectively (Figure 4, Table 2).
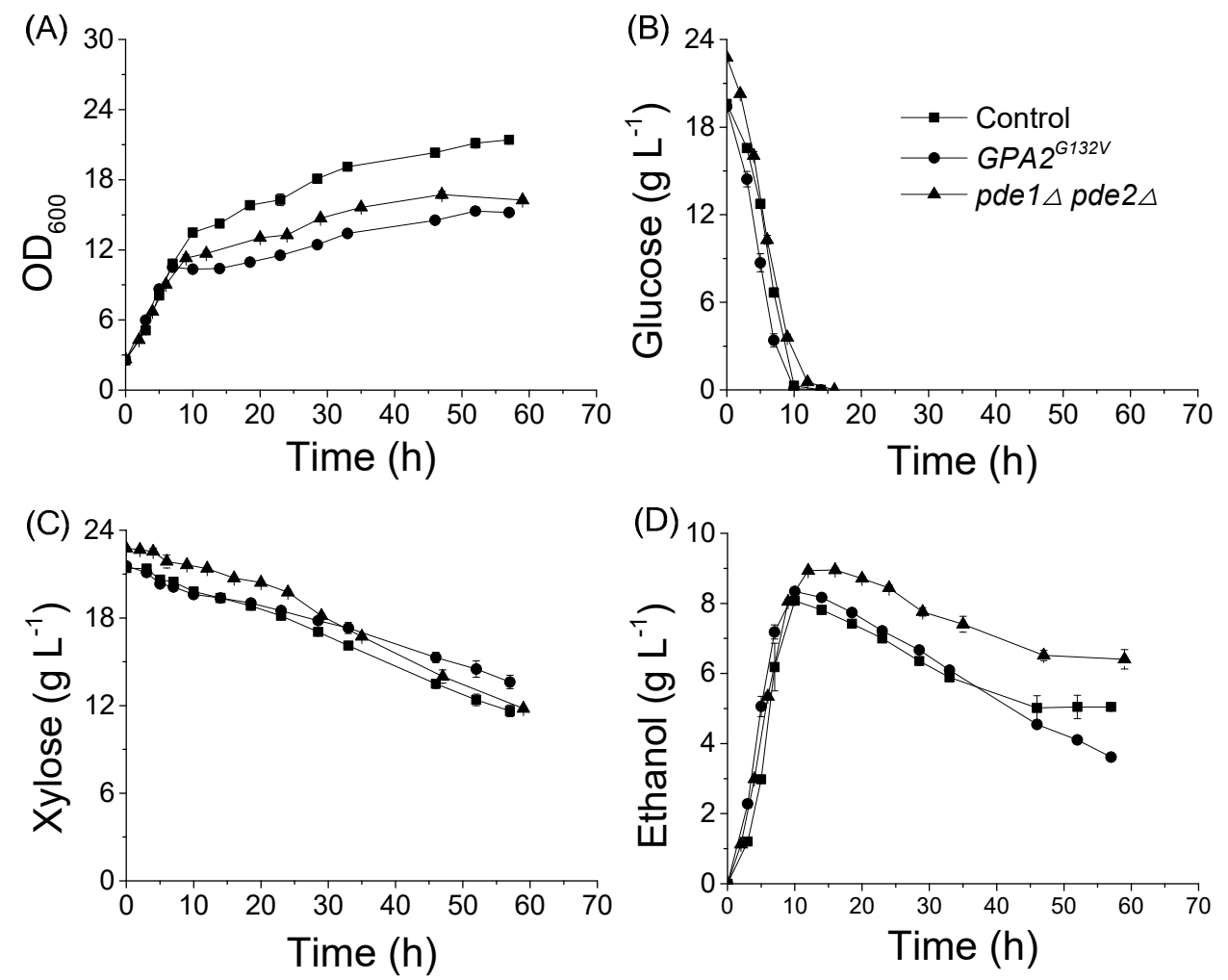

Figure 4. Xylose and glucose co-fermentation characteristics of recombinant $S$. cerevisiae strains. The (A), growth; (B) glucose consumption; (C), xylose consumption; and (D), ethanol production of strains. BSL06(GPA2 $\left.{ }^{G 132 V}\right)(\bullet)$, BSL16 (pde1 $\Delta$ pde2 $\left.\Delta\right)(\boldsymbol{\Delta})$, and the control BSL01 (घ). Cells with initial $\mathrm{OD}_{600}$ of $2.5\left(\approx 0.5 \mathrm{~g} \mathrm{~L}^{-1}\right.$ biomass) were cultured in SC-URA medium supplemented with $20 \mathrm{~g} \mathrm{~L}^{-1}$ xylose and $20 \mathrm{~g} \mathrm{~L}^{-1}$ glucose at $30^{\circ} \mathrm{C}$ and $200 \mathrm{rpm}$ in shake flasks. Data are the mean values of triplicates.

\subsection{Weak Responses of Rgt2 and Snf3 to High Concentrations of Extracellular Xylose}

To investigate if the Rgt2/Snf3-Rgt1 pathway, another well-known glucose signaling pathway, can respond to extracellular xylose and induce expression of transporter genes, the transcriptional levels of genes HXT1 and HXT2 in yeast cells cultured on different carbon sources were measured by quantitative PCR.

A previous study reported that a high concentration of glucose $\left(40 \mathrm{~g} \mathrm{~L}^{-1}\right)$ induced expression of HXT1, and the main sensor of the high-level glucose in S. cerevisiae was Rgt2 [22]. In addition, a low concentration of glucose $\left(1 \mathrm{~g} \mathrm{~L}^{-1}\right)$ induced expression of $H X T 2$, and the main sensor of the low-level glucose was Snf3 [22]. Our results supported these findings (Figure 5). HXT1 and HXT2 transcriptional levels in the wild type strain CEN.PK 113-5D grown in the medium containing $40 \mathrm{~g} \mathrm{~L}^{-1}$ glucose were approximately 400 and 25 times greater than those observed in cells cultured in a medium containing glycerol as the sole carbon source (hereafter referred to as glycerol medium), respectively. Furthermore, in comparison to HXT1 expression in the wild type exposed to the high concentration of glucose, 
expression in rgt $2 \Delta$ mutants was greater by $58 \%$ and unaffected by the deletion of SNF3. In a similar comparison, HXT2 expression induced by $1 \mathrm{~g} \mathrm{~L}^{-1}$ glucose was lower by $82 \%$ in $s n f 3 \Delta$ mutants and unaffected by the deletion of RGT2.
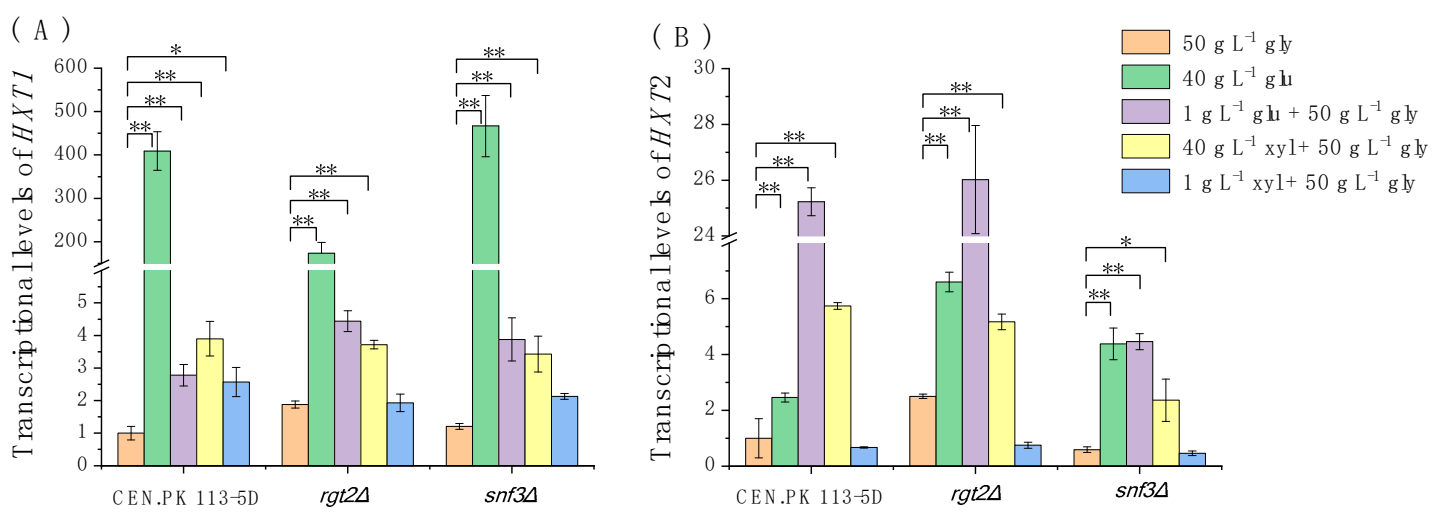

Figure 5. The transcriptional levels of (A) HXT1 and (B) HXT2 in yeast strains. The gene transcript levels in CEN.PK 113-5D (wild type) cells cultured in $50 \mathrm{~g} \mathrm{~L}^{-1}$ glycerol were defined as 1 and all other data were relativized to the level of the wild type cultured in $50 \mathrm{~g} \mathrm{~L}^{-1}$ glycerol. Abbreviations: gly, glycerol; glu, glucose; xyl, xylose. Cells with initial $\mathrm{OD}_{600}$ of 0.2 were cultured at $30^{\circ} \mathrm{C}$ in shake flasks that were agitated at $200 \mathrm{rpm}$. Cells were collected when the $\mathrm{OD}_{600}$ reached $0.8-1.0$ and then their mRNA was extracted. The experiments were performed in triplicate. ${ }^{*}$, fold change $\geq 2, p<0.05$; **, fold change $\geq 2, p<0.005$.

The results illustrate additional relationships of the four genes and the different carbon sources (Figure 5). The presence of $1 \mathrm{~g} \mathrm{~L}^{-1}$ glucose, $40 \mathrm{~g} \mathrm{~L}^{-1}$ xylose, or $1 \mathrm{~g} \mathrm{~L}^{-1}$ xylose also increased the transcriptional levels of HXT1 in CEN.PK 113-5D, although the levels were much lower than the level in which $40 \mathrm{~g} \mathrm{~L}^{-1}$ glucose was present. Thus, all four carbohydrate conditions can induce the expression of HXT1. However, deletion of RGT2 or SNF3 reduced expression of HXT1 in strains cultured in $1 \mathrm{~g} \mathrm{~L}^{-1}$ xylose, the weak response of the strains to the low xylose concentration $\left(1 \mathrm{~g} \mathrm{~L}^{-1}\right)$ may be a cumulative effect that involves these two sensors. Exposure to $40 \mathrm{~g} \mathrm{~L}^{-1}$ glucose and $40 \mathrm{~g} \mathrm{~L}^{-1}$ xylose also raised transcriptional levels of HXT2 in CEN.PK 113-5D, although the levels were much lower than the exposure to $1 \mathrm{~g} \mathrm{~L}^{-1}$ glucose. By contrast, the signal from $1 \mathrm{~g} \mathrm{~L}^{-1}$ xylose was likely too weak to induce expression of HXT2. Furthermore, deletion of SNF3 significantly weakened the expression of HXT2 in the yeast cultured in $1 \mathrm{~g} \mathrm{~L}^{-1}$ glucose or $40 \mathrm{~g} \mathrm{~L}^{-1}$ xylose, while deletion of RGT2 did not weaken expression of HXT2. These results suggest that S. cerevisiae mainly depends on Snf3 to sense a high concentration of xylose $\left(40 \mathrm{~g} \mathrm{~L}^{-1}\right)$, similar to its Snf3-dependent response to the low level of glucose, though the response was clearly much weaker than the response to glucose.

\subsection{Deleting RGT1 Enhanced Xylose Utilization in S. cerevisiae by Upregulating the Expression of Hexose Transporter Genes}

Rgt1, a transcription repressor of HXTs, is phosphorylated when the glucose signal is transmitted into the cell through Rgt2 and Snf3, and then released from the promoters of HXTs; therefore, it derepresses the expression of hexose transporters. Thus, to simulate the condition that glucose signals have occurred, $r g t 1$ was deleted in strain BSL01. The qPCR results indicate that deletion of RGT1 increased transcriptional levels of HXT1 and HXT2 by $17.32 \pm 2.23$ - and $3.75 \pm 0.38$-fold, respectively, in cells cultured with $20 \mathrm{~g} \mathrm{~L}^{-1}$ xylose, but RGT1 had no notable effect on cells cultured with $20 \mathrm{~g} \mathrm{~L}^{-1}$ glucose. Furthermore, the results from fermentation experiments (Figure 6) showed that the specific xylose consumption rate $\left(\mathrm{r}_{\text {xylose }}\right)$ of BSL20 $(\mathrm{rgt1 \Delta})$ in xylose fermentation was $0.133 \pm 0.002 \mathrm{~g} \mathrm{~L}^{-1} \mathrm{~h}^{-1} \mathrm{~g}^{-1}$ DCW, which was $24 \%$ higher than the $\mathrm{r}_{\text {xylose }}$ of BSL01 $\left(0.107 \pm 0.006 \mathrm{~g} \mathrm{~L}^{-1} \mathrm{~h}^{-1} \mathrm{~g}^{-1} \mathrm{DCW}\right)$. Consistent with qPCR results, the RGT1 deletion did not affect glucose utilization. However, the $\mathrm{r}_{\mathrm{xylose}}$ of BSL20( $\left.r g t 1 \Delta\right)$ 
in the glucose-xylose co-fermentation during the xylose consumption phase $(20-72 \mathrm{~h})$ was $0.053 \pm$ $0.003 \mathrm{~g} \mathrm{~L}^{-1} \mathrm{~h}^{-1} \mathrm{~g}^{-1} \mathrm{DCW}$ and $23 \%$ higher than that of BSL01 (0.043 $\left.\pm 0.003 \mathrm{~g} \mathrm{~L}^{-1} \mathrm{~h}^{-1} \mathrm{~g}^{-1} \mathrm{DCW}\right)$.
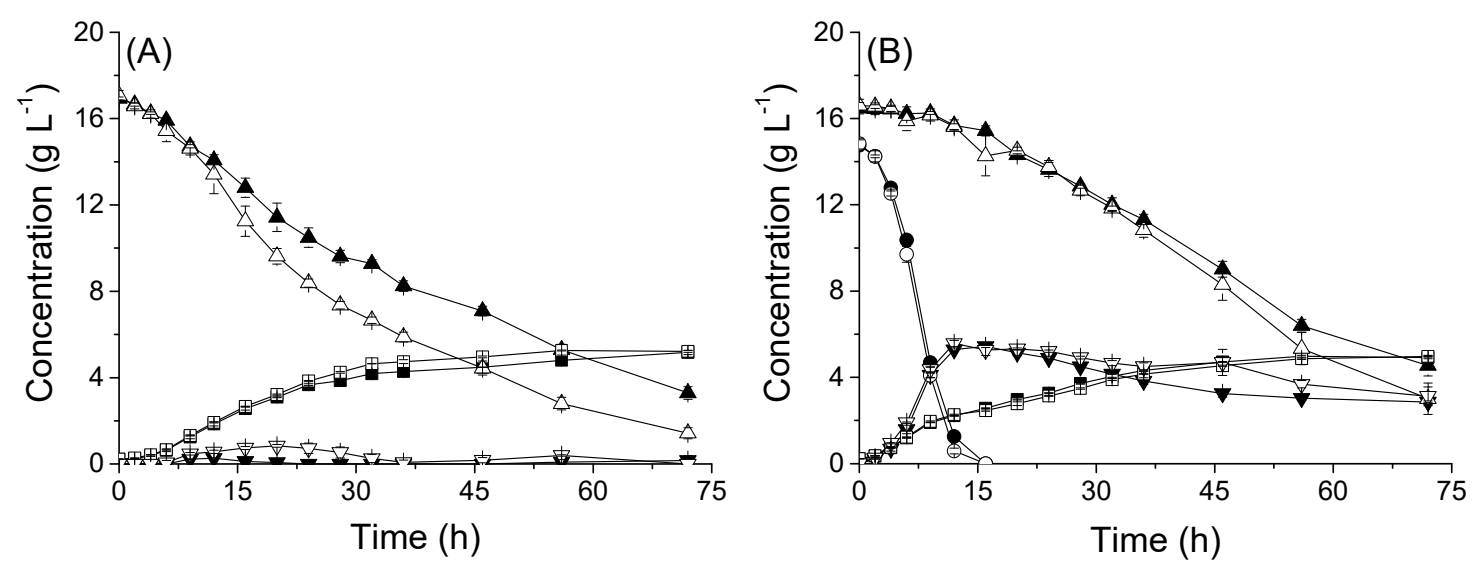

Figure 6. Fermentation characteristics of RGT1 deletion strain. Strains cultured in (A) $40 \mathrm{~mL}$ SC-URA with $20 \mathrm{~g} \mathrm{~L}^{-1}$ xylose or (B) $40 \mathrm{~mL}$ SC-URA with $20 \mathrm{~g} \mathrm{~L}^{-1}$ xylose and $20 \mathrm{~g} \mathrm{~L}^{-1}$ glucose. Cells with initial $\mathrm{OD}_{600}$ of $1\left(\approx 0.2 \mathrm{~g} \mathrm{~L}^{-1}\right.$ biomass) were agitated at $200 \mathrm{rpm}$ at $30^{\circ} \mathrm{C}$. The experiments were performed in triplicate. Symbols: $\square$, dry cell weight; $\bullet$, glucose; $\Delta \triangle$, xylose; $\nabla \nabla$, ethanol. Solid symbols represent the BSL01 strain and hollow symbols represent the mutant strain BSL20 (rgt1 $)$.

\section{Discussion}

Xylose is an important and abundant carbon source second to glucose in industrial fermentation processes to produce fuels and chemicals. However, S. cerevisiae is only able to efficiently metabolize glucose. Despite the many attempts to genetically modify the carbohydrate metabolism of yeast to obtain more efficient xylose fermentation rates, large gaps in our knowledge and understanding of the carbohydrate metabolic pathways and their mechanisms hamper our pursuit in developing recombinant strains that can exploit the potential energy from xylose as well as they do from glucose.

Hexose transporters and glycolysis, which are controlled by glucose signaling pathways, are important to xylose metabolic efficiency, and our previous work suggests that extracellular glucose signals can promote xylose utilization [18] (Figure A1). Despite extensive studies on glucose signaling pathways and their controls on glucose metabolism, less is known about how these signaling pathways may respond to xylose. Here, we demonstrated that $S$. cerevisiae cells can only weakly respond to xylose, which may limit its potential to metabolize xylose. Furthermore, we also demonstrated that simulating the occurrence of glucose signals in yeast strains with a mutation $\left(G P A 2^{G 132 V}\right)$ or deletions (PDE1 and PDE2, and RGT1) of specific genes found in two different glucose signaling pathways (cAMP-PKA and Rgt2/Snf3-Rgt1 pathways) are feasible strategies to enhance xylose utilization and/or ethanol production in yeast.

Brink et al. [25] developed a successful method by applying a green fluorescence protein gene (yEGFP3) to monitor effects of eight endogenous yeast promoters, which are found in the three major sugar metabolism pathways Snf3/Rgt2, Snf1/Mig1, and cAMP/PKA, on glucose and xylose signaling responses in yeast. They determined that only two of these promoters respond to xylose; the two successful promoters were the HXT2p/4p sensors of the Snf3/Rgt2 signaling pathway. We also measured the responses of the two promoters, HXT1 and HXT2, but in $r g t 2 \Delta$ and snf $3 \Delta$ mutants, as well as a strain with the wildtype Snf3/Rgt2 pathway. Our results revealed that the expression of $H X T 1$ responded to both high and low concentrations of xylose (50 and $1 \mathrm{~g} \mathrm{~L}^{-1}$, respectively), while the expression of HXT2 only responded to the high xylose concentration. Our results confirmed that the Snf3/Rgt2 pathway can minimally respond to xylose. Furthermore, we found that S. cerevisiae's response to the high xylose level is similar to its response to the low glucose level, which corroborates the findings of Osiro et al. [34]. 
Özcan et al. (1996) revealed that a dominant mutation in RGT2 and SNF3 causes constitutive induction of HXT gene expression, even in the absence of the inducer glucose, which suggests this mutation converts the glucose sensors into their glucose-bound form [22]. Furthermore, their study on the $\operatorname{rgt} 2 \Delta \operatorname{snf} 3 \Delta$ strain, as well as the $r g t 2 \Delta$ and snf $3 \Delta$ strains, revealed that HXT1 and HXT2 took even lower response to the glucose in the double mutant than in the single mutants, which confirmed that Snf3 and Rgt2 have separate but overlapping functions [35]. In the present work, deletion of either RGT2 or SNF3 reduced expression of HXT1 in strains cultured in $1 \mathrm{~g} \mathrm{~L}^{-1}$ xylose, which suggest that the weak response of the strains to the low xylose concentration $\left(1 \mathrm{~g} \mathrm{~L}^{-1}\right)$ may be a cumulative effect that involves these two sensors. Moreover, xylose can bind both Snf3 and Rgt2 and slightly alter their conformations. In contrast, deletion of SNF3 significantly weakened the expression of HXT2 in the yeast cultured in $40 \mathrm{~g} \mathrm{~L}^{-1}$ xylose, while deletion of RGT2 did not weaken expression of HXT2, suggesting that $S$. cerevisiae mainly depends on Snf3 to sense a high concentration of xylose $\left(40 \mathrm{~g} \mathrm{~L}^{-1}\right)$. Our results also showed that the response of cells to xylose was clearly much weaker than the response to glucose. This may be due to either a low affinity of xylose to Snf3/Rgt2 is low or the conformations of xylose-bound Snf3/Rgt2 are not close to the glucose-bound Snf3/Rgt2. To determine the cause, will require substantially greater research efforts in the future.

Here, we used a recombinant strain with xylose metabolic capacity. This strain was derived from CEN.PK-113-5D, which belongs to the family of the CEN.PK strain [27]. Reportedly, the CYR1 allele in CEN.PK strains encodes a mutant adenylate cyclase $\left(\mathrm{Cyr} 1^{\mathrm{K} 1876 \mathrm{M}}\right)$, and the constitutive activation of the cAMP pathway by Ras2 ${ }^{\mathrm{G} 19 \mathrm{~V}}$ and $\mathrm{Gpa} 2^{\mathrm{G} 132 \mathrm{~V}}$ is suppressed by this mutant [27]. Supporting this report, our result showed that the cAMP level and PKA activity of strain BSL08(RAS2 ${ }^{G 19 V}$ ) were not higher than those of the control [36]. However, although the cAMP level of the strain BSL06(GPA2 $\left.{ }^{\mathrm{G} 132 \mathrm{~V}}\right)$ showed an insignificant increase in xylose, the increased PKA activity in BSL06(GPA2G132V) cells cultured on glucose and xylose were observed. This may be due to Gpa2 inhibiting Gpb1 and 2, which inhibit PKA activity [37]. Moreover, deletion of both PDE1 and PDE2 increased PKA activity and xylose utilization. Recent works have reported that deletion of IRA2 inhibits PKA activity by negatively regulating RAS or $B C Y 1$ (a gene encoding a PKA inhibitor) and thus increases the specific xylose consumption rates (xylose consumed per unit of cell mass) of strains [14,15,38]. Our results directly support their viewpoint that active PKA benefits xylose metabolism in a certain way.

Moreover, we found that increasing PKA activity did not affect the specific growth rate of the yeast strain; however, it shortened the exponential growth phase and decreased biomass yield in glucose fermentation. High PKA activity promotes aging and early cell death and leads to a short lifespan $[39,40]$, and thus the high PKA activity may have been the cause of this observation. On the other hand, in xylose fermentation, the increased PKA activity did not affect the exponential growth phase and biomass yield of yeast. This may be due to that the PKA activity in strains (control and mutations) cultured in xylose are lower than that in the control strain cultured in glucose. However, the short lifespan should be avoided in ethanol production using materials containing both glucose and xylose. Therefore, increase PKA activity only when glucose is running out in glucose-xylose co-fermentation may be a way to enhance xylose utilization without shorten the lifespan of yeast cells.

Author Contributions: Investigation, M.W., H.L., S.W., H.W. and X.W.; resources, Y.S., X.B. and J.H.; formal analysis, M.W., H.L., S.W., H.W., X.W. and Y.S.; writing-original draft preparation, M.W.; writing-review and editing, Y.S.; supervision, Y.S., X.B. and W.L.; project administration, Y.S.; funding acquisition, Y.S. and X.B. All authors have read and agreed to the published version of the manuscript.

Funding: This research was funded by the National Key Research and Development Program of China (2018YFB1501702, 2018YFB1501401), the National Natural Science Foundation of China (No. 31770046, and No.31870063), the Major Program of Shandong Province Natural Science Foundation (No. ZR2018ZB0209), and the Key Research and Development project of Shandong Province (2017CXGC1105).

Acknowledgments: We apologize to colleagues whose work could not be cited due to space limitations.

Conflicts of Interest: The authors declare no conflict of interest. 


\section{Appendix A}

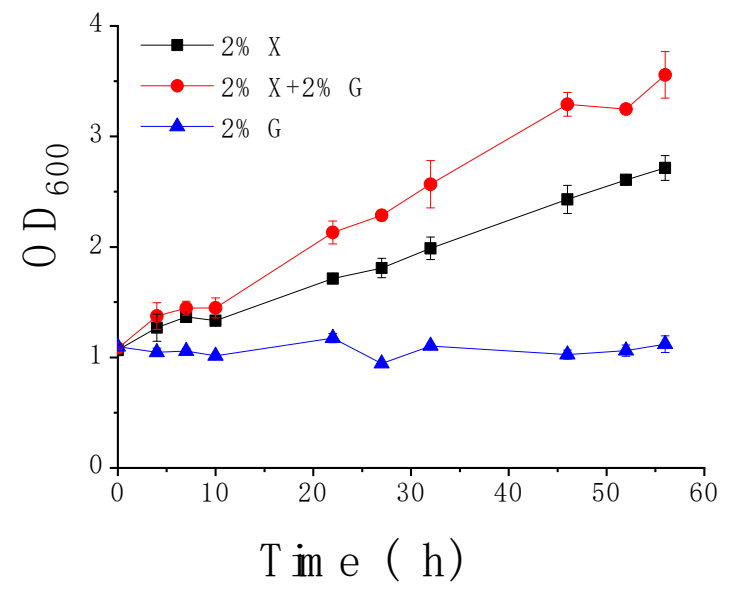

Figure A1. Extracellular glucose signals promoted xylose utilization. This strain derived from hxt-null strain EBY.VW4000 (Wieczorke et al., 1999), expressing the genes encoding the xylose reductase, xylitol dehydrogenase, and xylose transport of Mgt05196p (N360F), which transport xylose but not glucose. The seed cells were cultured in SD medium with $20 \mathrm{~g} \mathrm{~L}^{-1}$ glucose overnight, then collected, washed with sterile water, and inoculated into $40 \mathrm{~mL}$ of SD medium with $20 \mathrm{~g} \mathrm{~L}^{-1}$ D-xylose (घ), $20 \mathrm{~g} \mathrm{~L}^{-1}$ D-xylose and $20 \mathrm{~g} \mathrm{~L}^{-1}$ glucose (•), and $20 \mathrm{~g} \mathrm{~L}^{-1}$ glucose $(\mathbf{\Lambda})$. The error bars represent the standard deviation of the biological triplicates.

\section{Appendix B}

Table A1. The primers used in this study.

\begin{tabular}{|c|c|}
\hline Primers & Sequence $5^{\prime} \rightarrow 3^{\prime}$ \\
\hline \multicolumn{2}{|l|}{$\begin{array}{l}\text { For gene } \\
\text { expression }\end{array}$} \\
\hline BamHI-GPA2-1up & GCGCGGATCCATGGGTCTCTGCGCATCTTC \\
\hline GPA2-1dn $\quad 1$ & ACTTACCACTTTCAACGGCACCCAG \\
\hline GPA2-2up & CTGCTGGGTGCCGTTGAAAGTGGTAAG \\
\hline SbfI-GPA2-2dn & CGCGCCTGCAGGTCATTGTAACACTCCAGAGTCTTTC \\
\hline GRE3-ty1up & CAGATGACGAGAAGAAAGGTCACATC \\
\hline GRE3-ty1dn & CCGAAGGAGGAGTAAGCAACTAC \\
\hline KanMX-up0505 & ATATCCAAGTAGTTGCTTACTCCTCCTTCGGTAGGTCTAGAGATCTGTTTAGCTTGCC \\
\hline KanMX-dn0505 & CATTTTGAAGCTATGGTGTGTGGGCCACTAGTGGATCTGATATCACC \\
\hline GPA2-up0505 & GTGATATCAGATCCACTAGTGGCCCACACACCATAGCTTCAAAATGTTTC \\
\hline GPA2-dn0505 & GCCCATCTAAGCAATACTTGGGAAGCATGATTACGCCAAGCTTTAAC \\
\hline GRE3-ty2up & CGTAATCATGCTTCCCAAGTATTGCTTAGATGGGC \\
\hline GRE3-ty2dn & TCAGGCAAAAGTGGGGAATTTACC \\
\hline G-int-up & CCATTTGAAGAGAAATACCCTCCAG \\
\hline RAS-tylup & GAAAACGGGAAACAAGGTTCACATCAG \\
\hline RAS-ty1dn & CGACTTGTTCAAAGGCATTTTTTTTTCTGTATATCTCCTTTCAATTCGAAAACGG \\
\hline Rasup1 & AAGAGAGTACAAGCTAGTCGTCGTTGGTGGTGTTGGTGTTGGTAAATCTGC \\
\hline Rasup2 & ATGCCTTTGAACAAGTCGAACATAAGAGAGTACAAGCTAGTCGTCG \\
\hline$R A S$-up & GAATTGAAAGGAGATATACAGAAAAAAAAATGCCTTTGAACAAGTCGAAC \\
\hline$R A S-\mathrm{dn}$ & AGCGTACGAAGCTTCAGCTTTAACTTATAATACAACAGCCACCCGATC \\
\hline $\mathrm{K}-R A S$-up & AGTTAAAGCTGAAGCTTCGTACGCTG \\
\hline $\mathrm{K}-R A S-\mathrm{dn}$ & GCGTTTCTACAACTATTTCCTTTTTAGCATAGGCCACTAGTGGATCTG \\
\hline RAS-ty2up & CCACTAGTGGCCTATGCTAAAAAGGAAATAGTTGTAGAAACGCTAAGACG \\
\hline RAS-ty2dn & CTCTGGAACGTCCTCATATTCACC \\
\hline seq-rasR & GTATTCTGGGCCTCCATGTC \\
\hline int- $Y$ & CAGAAGGACCTTTTCATTCACC \\
\hline RuXI-up & GGATCCATGGCAAAAGAATATTTTCCGTTTAC \\
\hline$R u X I-\mathrm{dn}$ & CCTGCAGGTTATTTGCAGTGGAGGGCG \\
\hline
\end{tabular}


Table A1. Cont.

\begin{tabular}{|c|c|}
\hline Primers & Sequence $5^{\prime} \rightarrow 3^{\prime}$ \\
\hline \multicolumn{2}{|l|}{ For gene knockout } \\
\hline PDE1-ty1up & GAATGTACCAGCTACGGGAGATG \\
\hline PDE1-ty1dn & CGTACGAAGCTTCAGCTCAGCCCACTAATATGGTCCAGATG \\
\hline K-PDE1-up & CATCTGGACCATATTAGTGGGCTGAGCTGAAGCTTCGTACGCTG \\
\hline $\mathrm{K}-P D E 1-\mathrm{dn}$ & CTAATATACCCTTGAGATGCACAAGCGCATAGGCCACTAGTGGATCTG \\
\hline PDE1-ty2up & GATCCACTAGTGGCCTATGCGCTTGTGCATCTCAAGGGTATATTAG \\
\hline PDE1-ty2dn & СТCAAGTCTCСТAAGTTCСТСТСС \\
\hline PDE2-tylup & ATGTCCACCCTTTTTCTGATTGG \\
\hline PDE2-ty1dn & AGCGTACGAAGCTTCAGCTCTCTCGTGTATGATCTATCGCAG \\
\hline $\mathrm{K}-P D E 2$-up & TCTGCGATAGATCATACACGAGAGAGCTGAAGCTTCGTACGCTG \\
\hline $\mathrm{K}-P D E 2-\mathrm{dn}$ & СТATCCTCATACTGAGAATGCAATGCGCATAGGCCACTAGTGGATCTG \\
\hline PDE2-ty2up & GATCCACTAGTGGCCTATGCGCATTGCATTCTCAGTATGAGGATAG \\
\hline$P D E 2-\operatorname{ty} 2 \mathrm{dn}$ & CGTTTGGAATATGCGGATGGTC \\
\hline KanMXhomoup-F & TGTGACGTGGCTTATGAGCACCAG \\
\hline KanMXhomoup-R & AGTACAAGGGAGAGGCGATTTCCAACG \\
\hline KanMXhomodn-F & ATGCTCССTTCTCCTGTAGGTCAGG \\
\hline KanMXhomodn-R & TGGCAATGGCAATAGTGATGGCACC \\
\hline KanMX-F & GGAAATCGCCTCTCCCTTGTACTGACATGGAGGCCCAGAATAC \\
\hline KanMX-R & CTGACCTACAGGAGAAGGGAGCATCAGTATAGCGACCAGC \\
\hline SNF3-1 & AGTGGCGTATTGGCCTTGTT \\
\hline SNF3-2 & GCCGAGGATAGGACTATTGTCTAG \\
\hline SNF3-3 & CAATAGTCCTATCCTCGGCACGCGGCCGCCAGCTGAAGCTTCG \\
\hline SNF3-4 & GTAACCCAGAATCATGGACTGGACCGGCAGATCCGCGGCCGCA \\
\hline SNF3-5 & CCAGTCCATGATTCTGGGTTACTG \\
\hline SNF3-6 & CAACAACCAGCACCTTACGTCTAC \\
\hline RGT2-1 & CTGTTCCTGCATCGTCCATCGGC \\
\hline RGT2-2 & CGGCAGGTAGTCACCGTTGAGTC \\
\hline RGT2-3 & TCAACGGTGACTACCTGCCGACGCGGCCGCCAGCTGAAGCTTCG \\
\hline RGT2-4 & CTTGGATCTTCGATCGGGAGGCCACCGGCAGATCCGCGGCCGCATAG \\
\hline RGT2-5 & GGCCTCCCGATCGAAGATCCAAG \\
\hline RGT2-6 & ACTGAAGGCGACGTTGACGGC \\
\hline \multicolumn{2}{|l|}{ For qPCR } \\
\hline Actin-F & CAAACCGCTGCTCAATCTTC \\
\hline Actin-R & AGTTTGGTCAATACCGGCAG \\
\hline HXT1-qPCR-F & GTCGGTATGGTCTGCTGTTATG \\
\hline HXT1-qPCR-R & ACAGTTACCAGCACCCTTTG \\
\hline HXT2-qPCR-F & GGCTCTCAACAAACTTCTATCCAC \\
\hline HXT2-qPCR-R & GGGAGTTCAGCGTTAGTGTATTC \\
\hline
\end{tabular}

\section{References}

1. Kwak, S.; Jo, J.H.; Yun, E.J.; Jin, Y.S.; Seo, J.H. Production of biofuels and chemicals from xylose using native and engineered yeast strains. Biotechnol. Adv. 2019, 37, 271-283. [CrossRef]

2. Jansen, M.L.A.; Bracher, J.M.; Papapetridis, I.; Verhoeven, M.D.; de Bruijn, H.; de Waal, P.P.; van Maris, A.J.A.; Klaassen, P.; Pronk, J.T. Saccharomyces cerevisiae strains for second-generation ethanol production: From academic exploration to industrial implementation. FEMS Yeast Res. 2017, 17, fox044. [CrossRef] [PubMed]

3. Hou, J.; Qiu, C.; Shen, Y.; Li, H.; Bao, X. Engineering of Saccharomyces cerevisiae for the efficient co-utilization of glucose and xylose. FEMS Yeast Res. 2017, 17, fox034. [CrossRef] [PubMed]

4. Walfridsson, M.; Anderlund, M.; Bao, X.; Hahn-Hagerdal, B. Expression of different levels of enzymes from the Pichia stipitis XYL1 and XYL2 genes in Saccharomyces cerevisiae and its effects on product formation during xylose utilisation. Appl. Microbiol. Biotechnol. 1997, 48, 218-224. [CrossRef] [PubMed]

5. Kuyper, M.; Harhangi, H.R.; Stave, A.K.; Winkler, A.A.; Jetten, M.S.; de Laat, W.T.; den Ridder, J.J.; Op den Camp, H.J.; van Dijken, J.P.; Pronk, J.T. High-level functional expression of a fungal xylose isomerase: The key to efficient ethanolic fermentation of xylose by Saccharomyces cerevisiae? FEMS Yeast Res. 2003, 4, 69-78. [CrossRef] 
6. Toivari, M.H.; Aristidou, A.; Ruohonen, L.; Penttila, M. Conversion of xylose to ethanol by recombinant Saccharomyces cerevisiae: Importance of xylulokinase (XKS1) and oxygen availability. Metab. Eng. 2001, 3, 236-249. [CrossRef] [PubMed]

7. Johansson, B.; Hahn-Hagerdal, B. The non-oxidative pentose phosphate pathway controls the fermentation rate of xylulose but not of xylose in Saccharomyces cerevisiae TMB3001. FEMS Yeast Res. 2002, 2, 277-282. [PubMed]

8. Zhou, H.; Cheng, J.S.; Wang, B.L.; Fink, G.R.; Stephanopoulos, G. Xylose isomerase overexpression along with engineering of the pentose phosphate pathway and evolutionary engineering enable rapid xylose utilization and ethanol production by Saccharomyces cerevisiae. Metab. Eng. 2012, 14, 611-622. [CrossRef]

9. Kuyper, M.; Toirkens, M.J.; Diderich, J.A.; Winkler, A.A.; van Dijken, J.P.; Pronk, J.T. Evolutionary engineering of mixed-sugar utilization by a xylose-fermenting Saccharomyces cerevisiae strain. FEMS Yeast Res. 2005, 5, 925-934. [CrossRef]

10. Qi, X.; Zha, J.; Liu, G.G.; Zhang, W.; Li, B.Z.; Yuan, Y.J. Heterologous xylose isomerase pathway and evolutionary engineering improve xylose utilization in Saccharomyces cerevisiae. Front. Microbiol. 2015, 6, 1165. [CrossRef]

11. Shen, Y.; Chen, X.; Peng, B.; Chen, L.; Hou, J.; Bao, X. An efficient xylose-fermenting recombinant Saccharomyces cerevisiae strain obtained through adaptive evolution and its global transcription profile. Appl. Microbiol. Biotechnol. 2012, 96, 1079-1091. [CrossRef] [PubMed]

12. Peng, B.; Shen, Y.; Li, X.; Chen, X.; Hou, J.; Bao, X. Improvement of xylose fermentation in respiratory-deficient xylose-fermenting Saccharomyces cerevisiae. Metab. Eng. 2012, 14, 9-18. [CrossRef] [PubMed]

13. Hou, J.; Jiao, C.; Peng, B.; Shen, Y.; Bao, X. Mutation of a regulator Ask10p improves xylose isomerase activity through up-regulation of molecular chaperones in Saccharomyces cerevisiae. Metab. Eng. 2016, 38, 241-250. [CrossRef] [PubMed]

14. Sato, T.K.; Tremaine, M.; Parreiras, L.S.; Hebert, A.S.; Myers, K.S.; Higbee, A.J.; Sardi, M.; McIlwain, S.J.; Ong, I.M.; Breuer, R.J.; et al. Directed Evolution Reveals Unexpected Epistatic Interactions That Alter Metabolic Regulation and Enable Anaerobic Xylose Use by Saccharomyces cerevisiae. PLoS Genet. 2016, 12, e1006372.

15. Myers, K.S.; Riley, N.M.; MacGilvray, M.E.; Sato, T.K.; McGee, M.; Heilberger, J.; Coon, J.J.; Gasch, A.P. Rewired cellular signaling coordinates sugar and hypoxic responses for anaerobic xylose fermentation in yeast. PLoS Genet. 2019, 15, e1008037. [CrossRef]

16. Wei, S.; Liu, Y.; Wu, M.; Ma, T.; Bai, X.; Hou, J.; Shen, Y.; Bao, X. Disruption of the transcription factors Thi2p and Nrm1p alleviates the post-glucose effect on xylose utilization in Saccharomyces cerevisiae. Biotechnol. Biofuels 2018, 11, 112. [CrossRef]

17. Salusjarvi, L.; Kankainen, M.; Soliymani, R.; Pitkanen, J.P.; Penttila, M.; Ruohonen, L. Regulation of xylose metabolism in recombinant Saccharomyces cerevisiae. Microb. Cell Fact. 2008, 7, 18. [CrossRef]

18. Wang, C.; Bao, X.; Li, Y.; Jiao, C.; Hou, J.; Zhang, Q.; Zhang, W.; Liu, W.; Shen, Y. Cloning and characterization of heterologous transporters in Saccharomyces cerevisiae and identification of important amino acids for xylose utilization. Metab. Eng. 2015, 30, 79-88. [CrossRef]

19. Broach, J.R. Nutritional control of growth and development in yeast. Genetics 2012, 192, 73-105. [CrossRef]

20. Kim, J.H.; Roy, A.; Jouandot, D., II; Cho, K.H. The glucose signaling network in yeast. Biochim. Biophys. Acta Gen. Subj. 2013, 1830, 5204-5210. [CrossRef]

21. Thevelein, J.M.; de Winde, J.H. Novel sensing mechanisms and targets for the cAMP-protein kinase A pathway in the yeast Saccharomyces cerevisiae. Mol. Microbiol. 1999, 33, 904-918. [CrossRef] [PubMed]

22. Ozcan, S.; Dover, J.; Rosenwald, A.G.; Wolfl, S.; Johnston, M. Two glucose transporters in Saccharomyces cerevisiae are glucose sensors that generate a signal for induction of gene expression. Proc. Natl. Acad. Sci. USA 1996, 93, 12428-12432. [CrossRef] [PubMed]

23. Busti, S.; Coccetti, P.; Alberghina, L.; Vanoni, M. Glucose signaling-mediated coordination of cell growth and cell cycle in Saccharomyces cerevisiae. Sensors (Basel) 2010, 10, 6195-6240. [CrossRef] [PubMed]

24. Sharma, N.K.; Behera, S.; Arora, R.; Kumar, S.; Sani, R.K. Xylose transport in yeast for lignocellulosic ethanol production: Current status. J. Biosci. Bioeng. 2018, 125, 259-267. [CrossRef] [PubMed]

25. Brink, D.P.; Borgstrom, C.; Tueros, F.G.; Gorwa-Grauslund, M.F. Real-time monitoring of the sugar sensing in Saccharomyces cerevisiae indicates endogenous mechanisms for xylose signaling. Microb. Cell Fact. 2016, 15, 183. [CrossRef] [PubMed] 
26. Hou, J.; Shen, Y.; Jiao, C.; Ge, R.; Zhang, X.; Bao, X. Characterization and evolution of xylose isomerase screened from the bovine rumen metagenome in Saccharomyces cerevisiae. J. Biosci. Bioeng. 2016, 121, 160-165. [CrossRef] [PubMed]

27. Entian, K.-D.; Kötter, P. 25 Yeast Genetic Strain and Plasmid Collections. Methods Microbiol. 2007, 36, 629-666.

28. Guldener, U.; Heck, S.; Fiedler, T.; Beinhauer, J.; Hegemann, J.H. A new efficient gene disruption cassette for repeated use in budding yeast. Nucleic Acids Res. 1996, 24, 2519-2524. [CrossRef]

29. Pernambuco, M.B.; Winderickx, J.; Crauwels, M.; Griffioen, G.; Mager, W.H.; Thevelein, J.M. Glucose-triggered signalling in Saccharomyces cerevisiae: Different requirements for sugar phosphorylation between cells grown on glucose and those grown on non-fermentable carbon sources. Microbiology 1996, 142, 1775-1782. [CrossRef]

30. Livak, K.J.; Schmittgen, T.D. Analysis of relative gene expression data using real-time quantitative PCR and the 2(T)(-Delta Delta C) method. Methods 2001, 25, 402-408. [CrossRef]

31. Zahringer, H.; Thevelein, J.M.; Nwaka, S. Induction of neutral trehalase Nth1 by heat and osmotic stress is controlled by STRE elements and Msn2/Msn4 transcription factors: Variations of PKA effect during stress and growth. Mol. Microbiol. 2000, 35, 397-406. [CrossRef]

32. Rolland, F.; De Winde, J.H.; Lemaire, K.; Boles, E.; Thevelein, J.M.; Winderickx, J. Glucose-induced cAMP signalling in yeast requires both a G-protein coupled receptor system for extracellular glucose detection and a separable hexose kinase-dependent sensing process. Mol. Microbiol. 2000, 38, 348-358. [CrossRef]

33. Colombo, S.; Ma, P.; Cauwenberg, L.; Winderickx, J.; Crauwels, M.; Teunissen, A.; Nauwelaers, D.; de Winde, J.H.; Gorwa, M.F.; Colavizza, D. Involvement of distinct G-proteins, Gpa2 and Ras, in glucose-and intracellular acidification-induced cAMP signalling in the yeast Saccharomyces cerevisiae. EMBO J. 1998, 17, 3326-3341. [CrossRef]

34. Osiro, K.O.; Brink, D.P.; Borgstrom, C.; Wasserstrom, L.; Carlquist, M.; Gorwa-Grauslund, M.F. Assessing the effect of $\mathrm{d}$-xylose on the sugar signaling pathways of Saccharomyces cerevisiae in strains engineered for xylose transport and assimilation. FEMS Yeast Res. 2018, 18, fox096. [CrossRef]

35. Ozcan, S.; Dover, J.; Johnston, M. Glucose sensing and signaling by two glucose receptors in the yeast Saccharomyces cerevisiae. EMBO J. 1998, 17, 2566-2573. [CrossRef]

36. Vanhalewyn, M.; Dumortier, F.; Debast, G.; Colombo, S.; Ma, P.; Winderickx, J.; Van Dijck, P.; Thevelein, J.M. A mutation in Saccharomyces cerevisiae adenylate cyclase, Cyr1K1876M, specifically affects glucose- and acidification-induced cAMP signalling and not the basal cAMP level. Mol. Microbiol. 1999, 33, 363-376. [CrossRef]

37. Peeters, T.; Louwet, W.; Gelade, R.; Nauwelaers, D.; Thevelein, J.M.; Versele, M. Kelch-repeat proteins interacting with the Galpha protein Gpa2 bypass adenylate cyclase for direct regulation of protein kinase A in yeast. Proc. Natl. Acad. Sci. USA 2006, 103, 13034-13039. [CrossRef]

38. Osiro, K.O.; Borgstrom, C.; Brink, D.P.; Fjolnisdottir, B.L.; Gorwa-Grauslund, M.F. Exploring the xylose paradox in Saccharomyces cerevisiae through in vivo sugar signalomics of targeted deletants. Microb. Cell Fact. 2019, 18, 88. [CrossRef]

39. Longo, V.D.; Fabrizio, P. Chronological aging in Saccharomyces cerevisiae. Subcell. Biochem. 2012, 57, $101-121$.

40. Liu, Y.; Yang, F.; Li, S.; Dai, J.; Deng, H. Glutaredoxin Deletion Shortens Chronological Life Span in Saccharomyces cerevisiae via ROS-Mediated Ras/PKA Activation. J. Proteome Res. 2018, 17, 2318-2327. [CrossRef]

(C) 2020 by the authors. Licensee MDPI, Basel, Switzerland. This article is an open access article distributed under the terms and conditions of the Creative Commons Attribution (CC BY) license (http://creativecommons.org/licenses/by/4.0/). 